\title{
High resolution electron microscopy of bismuth oxides with perovskite layers $\dagger$
}

\author{
G N SUBBANNA and L GANAPATHI* \\ Materials Research Laboratory, ${ }^{*}$ Solid State and Structural Chemistry Unit, Indian \\ Institute of Science, Bangalore 560012 , India \\ MS received 28 January 1987
}

\begin{abstract}
Layered bismuth oxides of the general formula $\left(\mathrm{Bi}_{2} \mathrm{O}_{2}\right)^{2+}\left(A_{n-1} B_{n} \mathrm{O}_{3 n+1}\right)^{2-}$ where $A=\mathrm{Bi}$ or $\mathrm{Ba}, B=\mathrm{Ti}, \mathrm{Fe}, \mathrm{W}$ and $n=$ number of perovskite layers have been investigated by high resolution electron microscopy. Lattice images obtained for $n=1$ to 6 members show stacking of $(n-1)$ perovskite layers sandwiched between dark bands due to the $\left(\mathrm{Bi}_{2} \mathrm{O}_{2}\right)^{2+}$ layers. It has been possible to resolve the perovskite layer structures in some of the oxides. A highly ordered structure is observed upto the $n=3$ member, whereas higher members show superstructures, dislocations and stacking faults arising from the side-stepping of $\left(\mathrm{Bi}_{2} \mathrm{O}_{2}\right)^{2+}$ layers as well as ferroelectric domain walls.
\end{abstract}

Keywords. Electron microscopy; lattice images; defect structures; Aurivillius oxides.

\section{Introduction}

High resolution electron microscopy (HREM) is a powerful tool for the investigation of ultrastructure of solids in real space. Lattice imaging using an electron microscope provides novel information about the local structural defects and intergrowths which cannot otherwise be obtained from x-ray diffraction that reveals only the average structure (Anderson 1978; Rao and Thomas 1985; Rao 1985). Layered perovskite oxides containing bismuth, first described by Aurivillius (1950), have the general chemical formula $\left(\mathrm{Bi}_{2} \mathrm{O}_{2}\right)^{2+}\left(A_{n-1} B_{n} \mathrm{O}_{3 n+1}\right)^{2-}$ where $A$ is a bulky cation $\mathrm{Bi}^{3+}, \mathrm{Ba}^{2+}$ etc, $B$ is a smaller cation $\mathrm{Fe}^{3+}, \mathrm{Ti}^{4+}, \mathrm{W}^{6+}$ etc and $n$ corresponds to the number of corner-shared octahedra forming the $\left(A_{n-1} B_{n} \mathrm{O}_{3 n+1}\right)$ perovskite layers. The crystal structure of these oxides consists of $\left(\mathrm{Bi}_{2} \mathrm{O}_{2}\right)^{2+}$ layers interleaved with the $\left(A_{n-1} B_{n} \mathrm{O}_{3 n+1}\right)$ perovskite layers. All the oxides of the family are tetragonal (or with slight orthorhombic distortion) with the $a$ and $b$ parameters nearly equal to $\sqrt{2} a_{c}, a_{c}$ being the lattice parameter of the cubic perovskite subcell. The $c$ parameter in these solids varies progressively with increase in $n$. A structural projection of $n=5$ member is shown in figure 1 to illustrate some of the structural features. Positions of the bismuth atoms of the $\left[\mathrm{Bi}_{2} \mathrm{O}_{2}\right]^{2+}$ layers are close to virtual $A$ sites of the perovskite subcell. The pyramidal $\mathrm{BiO}_{4}$ groups share edges such that the successive perovskite layers are displaced by $1 / 2[110]_{c^{\prime}}$. Most of these Aurivillius oxides are ferroelectrics with high Curie temperatures and large values of the spontaneous polarization (Subba Rao 1962).

Earlier electron microscope studies of the Aurivillius oxides by Hutchison et al (1977) revealed interesting structural defects such as antiphase boundaries, dislocations and random intergrowth of different members. In this laboratory, we have

†Contribution No. 73 from Materials Research Labotatory. 
investigated several aspects of Aurivillius oxides, specially the intergrowth structures formed by them (Rao 1985; Gopalakrishnan et al 1984). In this paper, we present some of our HREM observations on the Aurivillius oxides chiefly containing $\mathrm{Bi}^{3+}$, $\mathrm{Ba}^{2+}$ cations at the $A$ site and $\mathrm{Ti}^{4+}, \mathrm{Fe}^{3+}$ and $\mathrm{W}^{6+}$ cations at the $B$ site.

\section{Experimental}

The various oxides of the Aurivillius family with $n=1$ to 6 were prepared starting from the appropriate mixtures of $\mathrm{Bi}_{2} \mathrm{O}_{3}, \mathrm{WO}_{3}, \mathrm{TiO}_{2}, \mathrm{Fe}_{2} \mathrm{O}_{3}$ and barium carbonate. Oxides prepared along with the evaluated lattice parameters are listed in table 1. High resolution electron microscopy (HREM) work was carried out in an electron microscope (JEOL JEM $200 \mathrm{CX}$ ) in the top entry configuration. Thin wedge-shaped crystals lying near a hole of the holey carbon grid were selected for the study. The crystals were brought to the required orientation using the $\pm 30^{\circ}$ goniometer. Images were recorded at $200 \mathrm{kV}$ with a primary magnification in the range of $3-5 \times 10^{5}$.

\section{Results and discussion}

One-dimensional lattice images obtained for $n=1$ to 5 members of the family are shown in figure 2. Dark fringes correspond to the $\left(\mathrm{Bi}_{2} \mathrm{O}_{2}\right)^{2+}$ layers and $n-1$ fringes

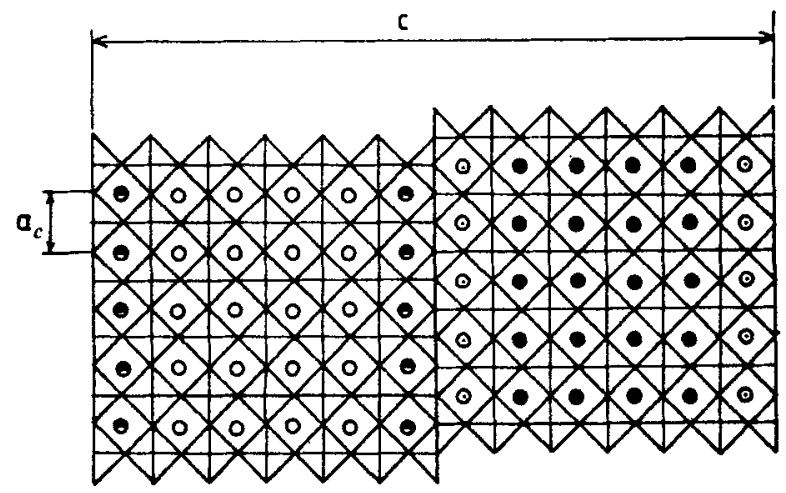

Figure 1. Structure of $\mathrm{Ba}_{2} \mathrm{Bi}_{4} \mathrm{Ti}_{5} \mathrm{O}_{18}$, projected on (101) of the pseudotetragonal cell! Each half of $c$ are at $y=0$, and $1 / 2 ; 0,0$ are $A$ cations at $y=0$ and $1 / 2 ; \odot, \odot$ are $\mathrm{Bi}$ in $\mathrm{Bi}_{2} \mathrm{O}_{2}$ layer at $y=0$ and $1 / 2$.

Table 1. Unit cell parameters of bismuth oxide-layered compounds studied.

\begin{tabular}{lcccc}
\hline & Perovskite & \multicolumn{3}{c}{ Lattice parameters $(\AA)$} \\
\cline { 3 - 5 } Compound & layers & $a$ & $b$ & $c$ \\
\hline $\mathrm{Bi}_{2} \mathrm{WO}_{6}$ & 1 & $5 \cdot 458$ & $5 \cdot 438$ & 16.43 \\
$\mathrm{BaBi}_{2} \mathrm{Nb}_{2} \mathrm{O}_{9}$ & 2 & 5.533 & 5.533 & $25 \cdot 55$ \\
$\mathrm{Bi}_{4} \mathrm{Ti}_{3} \mathrm{O}_{12}$ & 3 & 5.448 & $5 \cdot 411$ & $32 \cdot 83$ \\
$\mathrm{Bi}_{5} \mathrm{Ti}_{3} \mathrm{FeO}_{15}$ & 4 & 5.468 & $5 \cdot 464$ & $41 \cdot 23$ \\
$\mathrm{Ba}_{2} \mathrm{Bi}_{4} \mathrm{Ti}_{5} \mathrm{O}_{18}$ & 5 & 5.514 & 5.526 & $50 \cdot 37$ \\
$\mathrm{Bi}_{7} \mathrm{Ti}_{3} \mathrm{Fe}_{3} \mathrm{O}_{21}$ & 6 & 5.484 & 5.484 & 57.84 \\
\hline
\end{tabular}



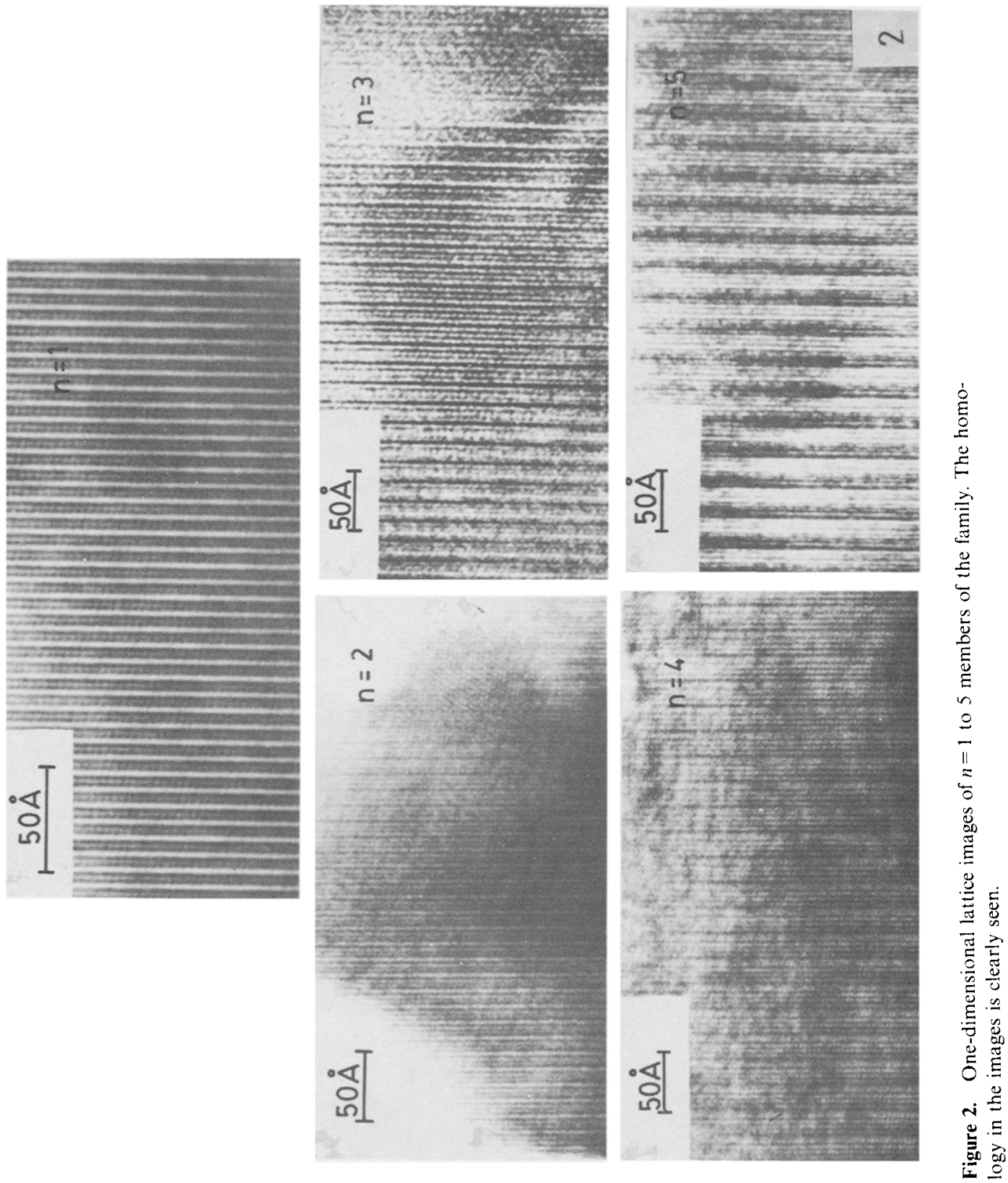
corresponding to perovskite layers between these two dark fringes are seen. A contrast reversal can occur in lattice images of thicker crystals. We can clearly see the homology in the images given in figure 2. Under favourable conditions, two-dimensional images (structure images) can be obtained which give a square-grid pattern of the perovskite structure with an octahedral separation of $0.38 \mathrm{~nm}$. High resolution structural images obtained for $\mathrm{Bi}_{2} \mathrm{WO}_{6}(n=1)$ and $\mathrm{Bi}_{7} \mathrm{Ti}_{3} \mathrm{Fe}_{3} \mathrm{O}_{21}(n=6)$ are shown in figures 3 and 4 respectively. The crystal orientation in both the images is $\langle 110\rangle$.
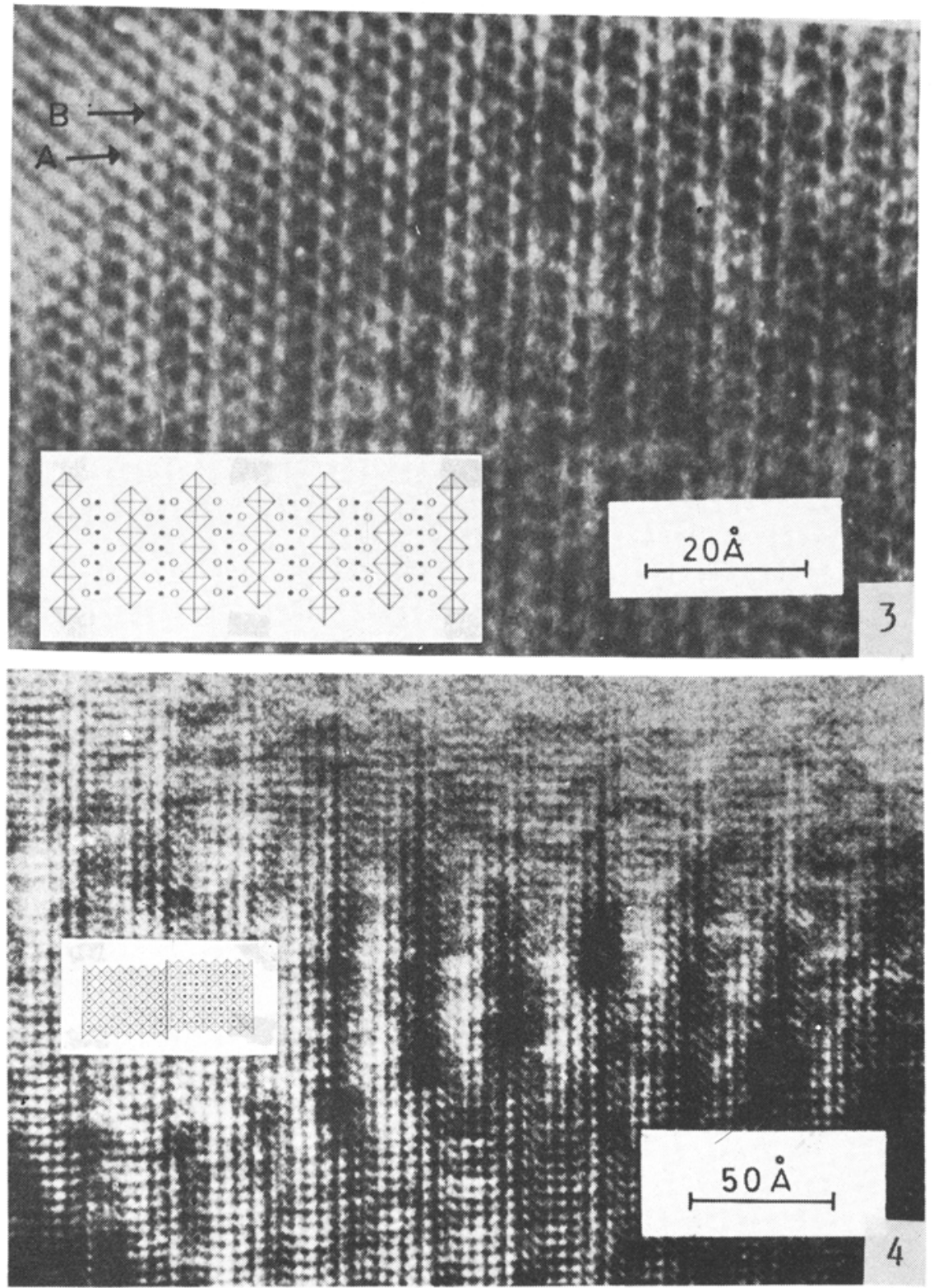

Figures 3 4. 3. HREM image of $\mathrm{Bi}_{2}, \mathrm{WO}_{n}(n=1)$. The inset shows the projected structure matching reasionably well with the image. 4. HREM image of $\mathrm{Bi}-\mathrm{Ti}_{3} \mathrm{Fe}_{3} \mathrm{O}_{21}(n=6)$. The inset shows the projected structure matching reasonably well with the image. 

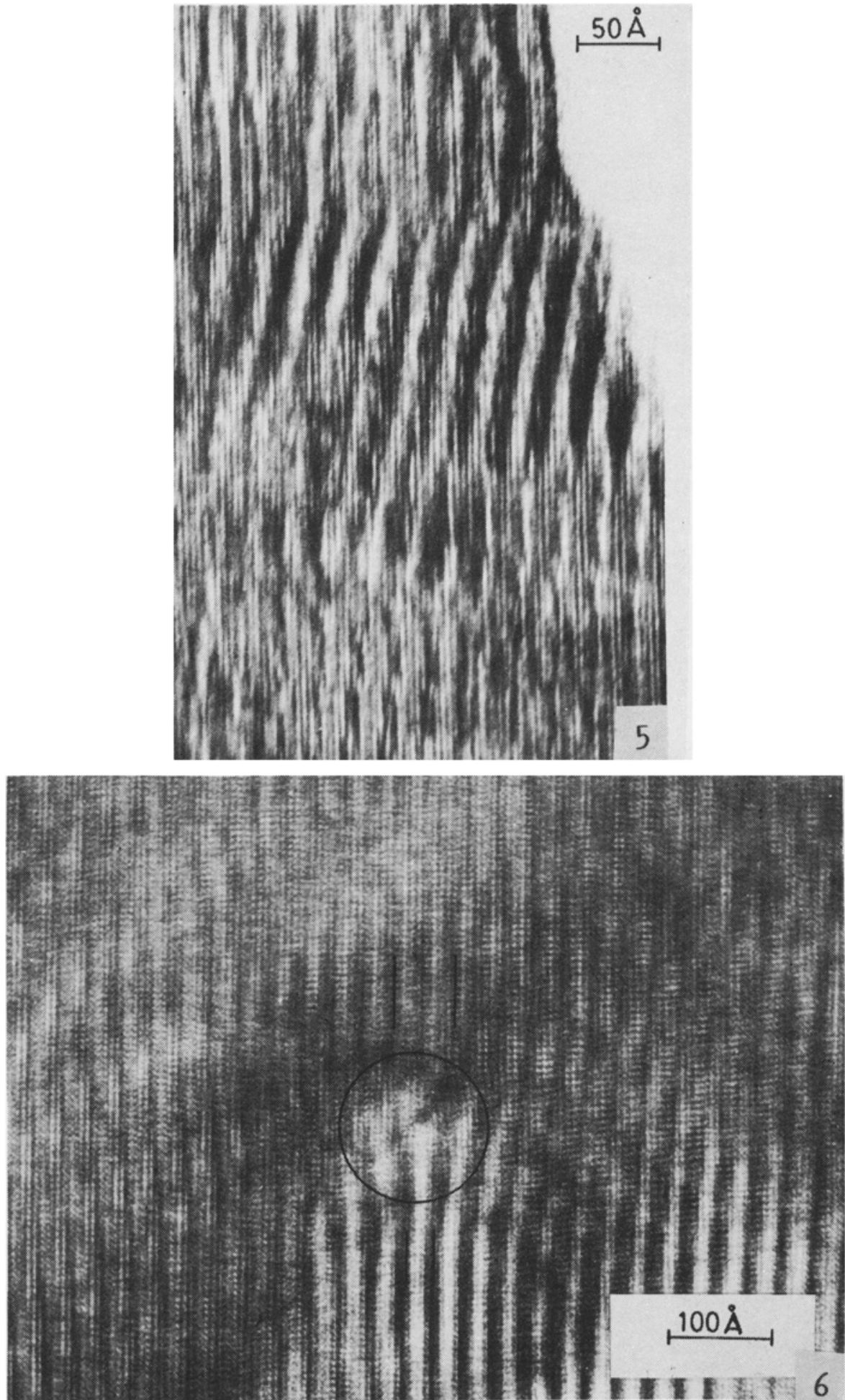

Figures 5-6. 5. Stacking fault in $\mathrm{Ba}_{2} \mathrm{Bi}_{4} \mathrm{Ti}_{5} \mathrm{O}_{14}(n=5)$ arising from the side stepping of the $\left(\mathrm{Bi}_{2} \mathrm{O}_{2}\right)^{2+}$ layers. 6. Lattice image of $\mathrm{Bi}_{-} \mathrm{Ti}_{3} \mathrm{Fe}_{3} \mathrm{O}_{21}(n=6)$ containing a dislocation. Note the associated strain field extending on either side of dislocation. 
The $\left(\mathrm{Bi}_{2} \mathrm{O}_{2}\right)^{2}+$ layers are aligned parallel to the beam and the perovskite layers are projected along $\langle 100\rangle$ of the cubic sub-cell. The projected structure of these oxides is shown in the insets of these figures; the HREM images can be matched with the projected images reasonably well. The structure images seem to reveal both the $A$ and $B$ cations as shown in figure 3. The image contrast is quite sensitive to orientation and the defocus condition, but under ideal conditions is able to yield atomic resolution. It may be noted that high resolution images of these oxides have not been described adequately in the literature hitherto (Tilley 1979).

Defect structures such as stacking faults, dislocations and antiphase boundaries are more commonly observed in the $n>3$ members of the Aurivillius family of oxides. Figure 5 illustrates the occurrence of stacking faults in a crystal of $\mathrm{Ba}_{2} \mathrm{Bi}_{4} \mathrm{Ti}_{5} \mathrm{O}_{18}$ $(n=5)$ arising from the side-stepping of the $\left(\mathrm{Bi}_{2} \mathrm{O}_{2}\right)^{2+}$ layers. Edge dislecations are also frequently observed in these oxides. The image in figure 6 shows a dislocation involving the termination of two perovskite slabs and the associated strain field extending upto 12 perovskite slabs. Domains caused by twinning are expected when the material is transformed to the ferroelectric state from the high-temperature paraelectric state. Domains with complex boundaries have been observed earlier in $n=4$ and 5 members of the family (Hutchison et al 1977). Figure 7 shows the domains observed by us in $n=4$ member of the family. The inset shows the composite electron diffraction pattern from the two adjacent domains. The dislocations observed in these materials may be related to ferroelectric distortions.

Oxides containing $\mathrm{Ti}^{4+}$ and $\mathrm{Fe}^{3+}$ in the $B$-site, namely $\mathrm{Bi}_{5} \mathrm{Ti}_{3} \mathrm{FeO}_{15}$ and $\mathrm{Bi}_{7} \mathrm{Ti}_{3} \mathrm{Fe}_{3} \mathrm{O}_{21}$ exhibit interesting superstructures in addition to the normal structure. Selected area electron diffraction (SAED) studies carried out on crystals exhibiting superstructures indicate doubling of unit cell in $\mathrm{Bi}_{5} \mathrm{Ti}_{3} \mathrm{FeO}_{15}$ and tripling in $\mathrm{Bi}_{7} \mathrm{Ti}_{3} \mathrm{Fe}_{3} \mathrm{O}_{21}$ (Subbanna et al 1987). The origin of the superstructures is likely to be within the perovskite layers, possibly due to $\mathrm{Fe} / \mathrm{Ti}$ ordering.

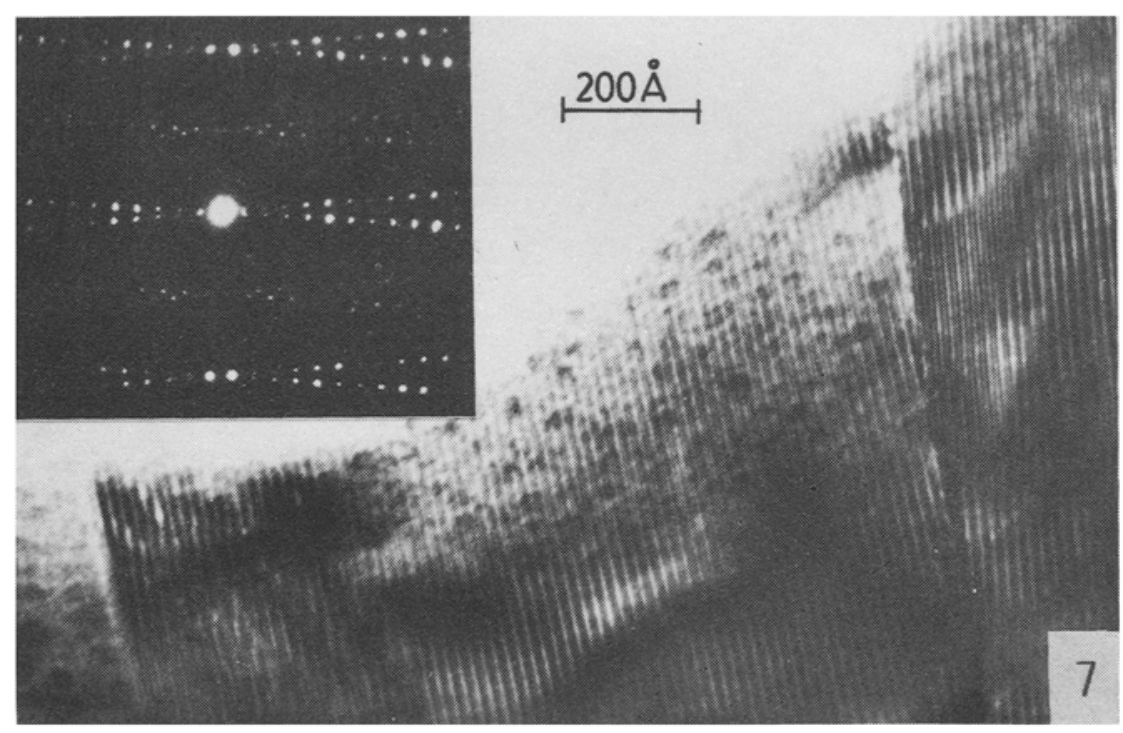

Figure 7. Lattice image of domains in $\mathrm{Bi}_{5} \mathrm{Ti}_{3} \mathrm{FeO}_{35}(n=4)$. The inset shows the composite SAED pattern. 
The formation of complex oxides as described above and other long period structures is a general phenomenon in solid state chemistry. The true complexity of these systems can only be revealed by high resolution electron microscopy. Long-range repulsive interaction arising from elastic forces is expected to be of importance in the formation of the Aurivillius family of oxides (Kikuchi 1979). The same forces also seem to be important in explaining recurrent intergrowth structures formed by adjacent members of this family of oxides (Rao 1985).

\section{Acknowledgement}

The authors thank Prof. C N R Rao for suggesting the problem and guidance.

\section{References}

Anderson J S 1978 Proc. Indian Acad. Sci. (Chem. Sci.) 87295

Aurivillius B 1950 Ark. Kemi. 2.519

Gopalakrishnan J, Ramanan A, Rao C N R, Jefferson D A and Smith D J 1984 J. Solid State Chem. 55101

Hutchison J L, Anderson J S and Rao C N R 1977 Proc. R. Soc. London A355 301

Kikuchi T 1979 Mater. Res. Bull. 141561

Rao C N R 1985 Bull. Mater. Sci. 7155

Rao C N R and Thomas J M 1985 Acc. Chem. Res. 18113

Subba Rao E C 1962 J. Am. Ceram. Soc. 45166

Subbanna G N, Ganapathi L, Rao C N R and Jefferson D A 1987 Mater. Res. Bull.22 205

Tilley R J D 1980 in Chemical physics of solids and surfaces (eds) M W Roberts and J M Thomas, Vol. 8, Specialist Periodic Report (London: Royal Society of Chemistry) 